\title{
Impact of the COVID-19 Pandemic on the Heart Disease Management of Health Structures in Senegal
}

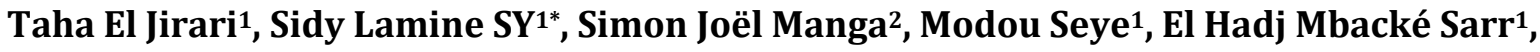 \\ Ibrahima Bara Diop1
}

${ }^{1}$ Cardiology Department, Fann National University Center, Cheikh Anta Diop University, Dakar, Senegal

${ }^{2}$ Cardiology Department, De la Paix Hospital, Assane Seck University, Ziguinchor, Senegal

Email: *lemzodiamono82@hotmail.com

How to cite this paper: El Jirari, T., SY, S.L., Manga, S.J., Seye, M., Sarr, E.H.M. and Diop, I.B. (2021) Impact of the COVID-19 Pandemic on the Heart Disease Management of Health Structures in Senegal. Open Access Library Journal, 8: e8176. https://doi.org/10.4236/oalib.1108176

Received: November 10, 2021 Accepted: December 11, 2021

Published: December 14, 2021

Copyright $\odot 2021$ by author(s) and Open Access Library Inc.

This work is licensed under the Creative Commons Attribution International License (CC BY 4.0).

http://creativecommons.org/licenses/by/4.0/

\begin{abstract}
Severe Acute Respiratory Syndrome-Coronavirus-2 broke out on December 31, 2019 in China. The virus is responsible for a pandemic from March 11, 2020 which has led to a reorganization of Cardiology structures in several countries around the world, including Senegal. Our study represents the first one in Senegal to assess the impact of this pandemic on Cardiology. This was a transversal survey-study conducted online over the period from August 29 to September 20, 2020 that collected qualitative data and included health professionals in Senegal managing heart disease. We collected 131 responses from Cardiology structures. The most represented region was that of Dakar (76\%) with a predominance of the public sector (84.4\%). A reduction in medical and interventional activity of at least $25 \%$ has been recorded. A drop in income due to the crisis was mentioned in $63.5 \%$ of responses. The unavailable drugs were mainly represented by digitalis (31.6\%). The tested professionals represented $44.1 \%, 12$ participants were positive, $21.8 \%$ were quarantined. The participants who mentioned that their patients could not benefit from a treatment in Cardiovascular Surgery represented 52\%, those who reported the death of some of their patients were $43.6 \%$. The identified manifestations were dominated by heart failure (53.9\%). The COVID-19 is responsible for a change in the care channels for Cardiology patients in Senegal, resulting in the requisition of health structures and reduction of medical and intervention activities. In times of pandemic, a reorganization of the Cardiology's teams and structures is necessary in order to anticipate the difficulties encountered in the care.
\end{abstract}

\section{Subject Areas}

Cardiology 


\section{Keywords}

COVID-19, Coronavirus, Impact, Cardiology, Senegal

\section{Introduction}

Coronaviruses belong to the Coronaviridae family of the order Nidovirales. They owe their name to the presence of crown-shaped virions on their outer surface. The coronavirus subgroups are alpha $(\alpha)$, beta $(\beta)$, gamma $(\gamma)$ and delta $(\delta)[1]$.

Severe Acute Respiratory Syndrome-Coronavirus-1 (SARS-CoV-1) killed 774 people in 2002-2003 after infecting 8096 people, mostly in China in Guangdong province and Hong Kong. The fatality rate was estimated at 9.6\%. The Middle East Respiratory Syndrome Coronavirus (MERS-CoV) was responsible in 2012, for a localized epidemic in the Middle East with a fatality rate of 38\% [2].

First named 2019-new Coronavirus (2019-nCov) by Chinese researchers, SARS-CoV- 2 is a virus belonging to the $\beta$ group of coronaviruses. It broke out on December 31, 2019 in the city of Wuhan in China, and the virus is responsible for a state of public health emergency of international concern from January 30, 2020. COVID-19 is the disease caused by SARS-CoV-2. It is responsible for a global pandemic from March 11, 2020 with more than 40 million positive cases and more than one million deaths identified to date [3]. It is the third global health threat linked to a coronavirus in less than twenty years [2].

In Senegal, it is responsible for more than 310 deaths and more than 15,410 positive cases at the date our study was carried out. The state of health emergency was declared in several countries including Senegal on March 23, 2020 [4].

COVID-19 has led to a reorganization of health structures and a change in the care of Cardiology patients in several countries around the world. The aim of our study was to assess the impact of the COVID-19 pandemic on establishments, medical staff as well as on the care of Cardiology patients in Senegal.

\section{Materials and Methods}

Our study was conducted in partnership with the Senegalese Cardiology Society (SOSECAR) and was carried out using the questionnaire tool on the website https://www.questionpro.com. The questionnaire to be completed online was distributed to health professionals practicing in Senegal and caring for patients with heart disease. It consisted of 21 questions dealing with 3 items related to the impact of the pandemic on: health structures; the staff and Cardiology patients. The detailed questionnaire can be viewed at the following link: https://www.questionpro.com/t/AQi2hZhqJ6.

Data were analyzed using SPSS Statistics 24 software. All data were represented as proportions and averages. For qualitative variables, comparison of percentages required Pearson's chi-square test with Yates correction for small samples. A $\mathrm{p}$ value $<0.05$ was considered statistically significant. 


\section{Results}

The questionnaire was sent to 161 people. It has been viewed 187 times. 131 responses were collected, 82 of which were complete. 39 of the 131 observations were insufficient because they did not answer questions relating to the main objective or specific objectives of the study or were uninterpretable.

Responses came from 10 regions of Senegal. No sightings were received from the regions of Kolda, Kaffrine, Kédougou and Sédhiou. Responses came mainly from the regions of Dakar (76\%), Diourbel (8.3\%) and Thiès (5.2\%).

There was a predominance of the public sector accounting for $84.4 \%$ of the participation rate, with a majority of Cardiologists (64.6\%).

Responses from University Hospital Centers (CHU) represented 56.6\%.

- Impact on the activity of structures:

More than half of the responses (51\%) indicated that there had been requisition of cabins, sectors or an entire Cardiology establishment for the treatment of patients with COVID-19.

A reduction in medical and interventional activity of at least $25 \%$ was recorded in the majority of cases (Figure 1).

A drop in the income of structures was mentioned in $63.5 \%$ of the responses. According to the participants, the drugs that were unavailable during confinement were mainly represented by digitalis (31.6\% of responses) Figure 2 .

- Impact on staff:

The majority of responses (70.8\%) indicated that staff worked in a risky environment.

Regarding Polymerase Chain Reaction (PCR) tests performed on staff, $44.1 \%$ of participants were tested and $12.6 \%$ were positive.

Among the participants the majority of the workforce was available and $21.87 \%$ were quarantined (Figure 3 ).

- Impact on patients:

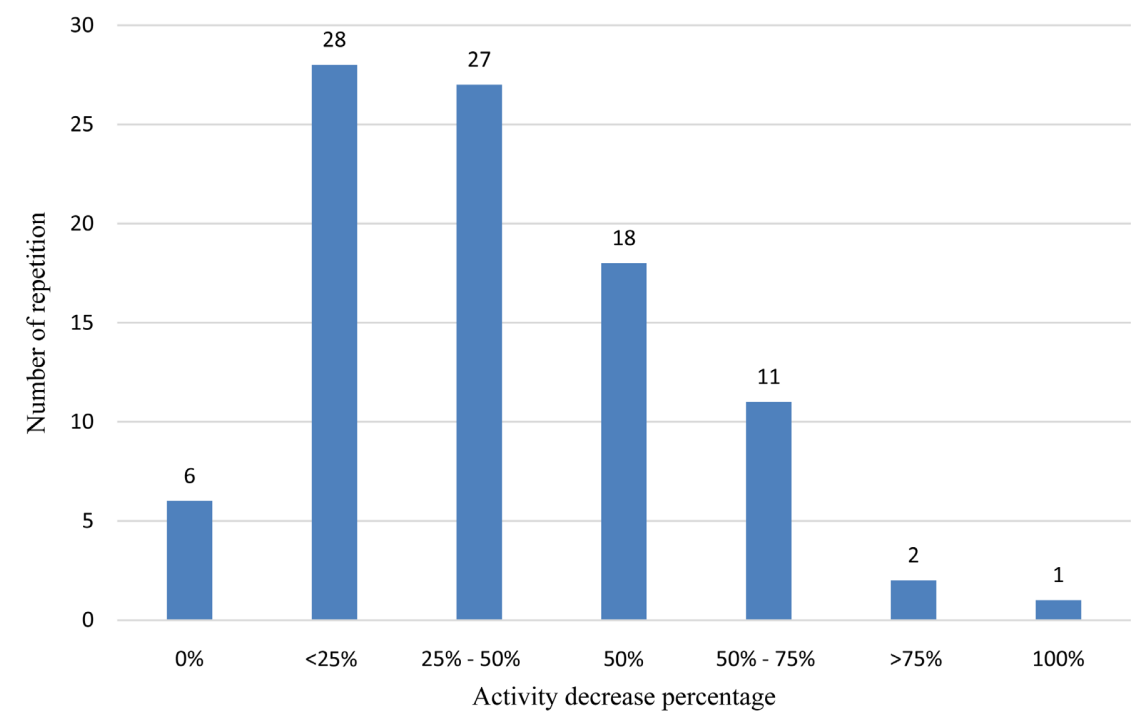

Figure 1. Distribution of responses by percentage decline in medical activity. 

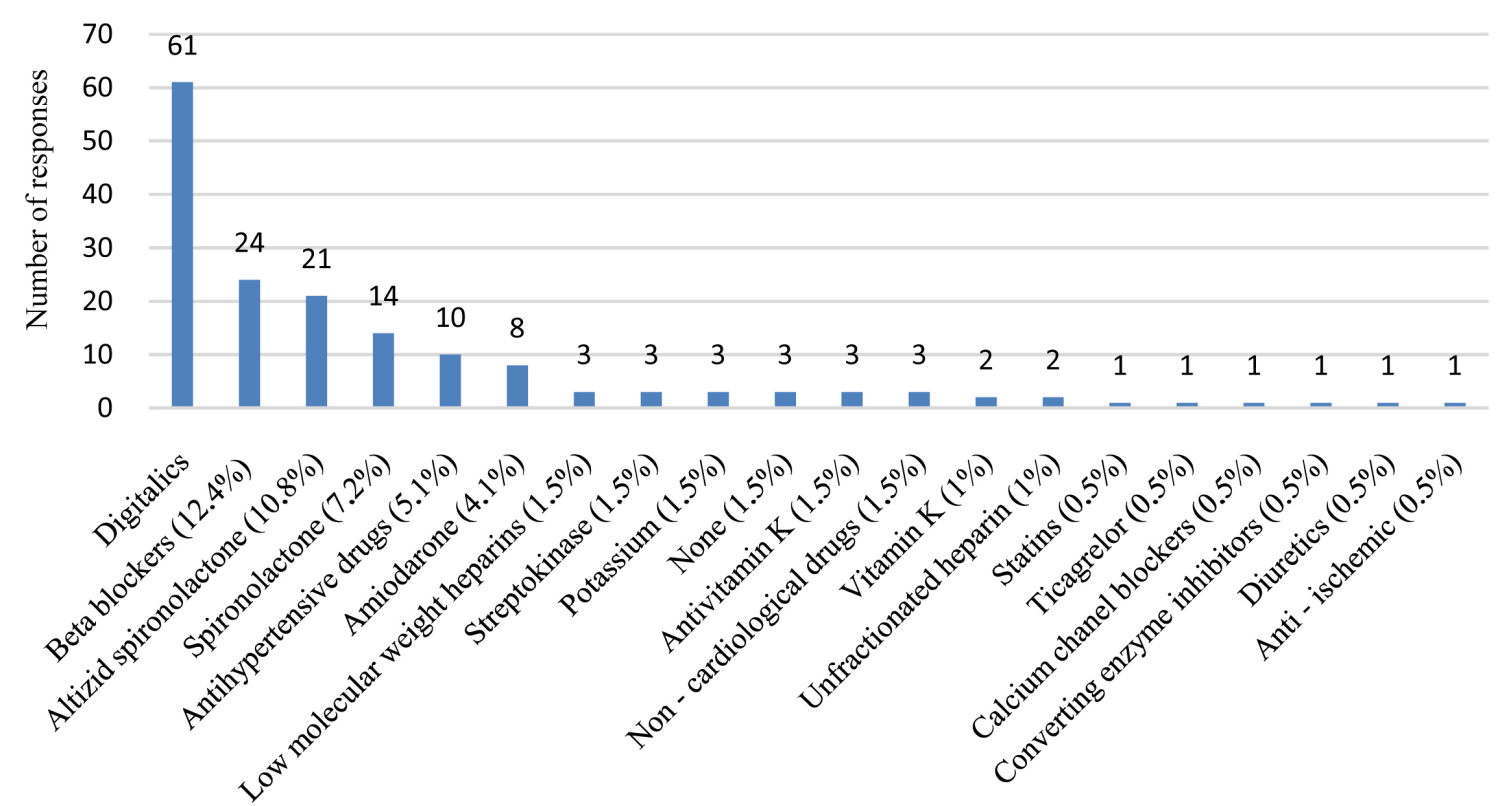

Unavailable drugs

Figure 2. Distribution of responses according to the type of drug out of stock during confinement.

Unvailable (quarantine)

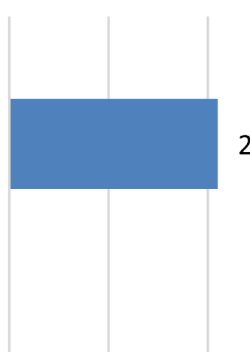

21

Available

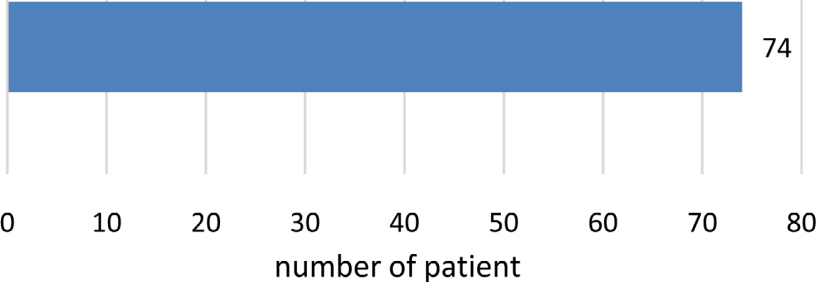

Figure 3. Distribution of the number of participants according to their availability.

The majority of participants $(75.5 \%)$ felt that some of their patients had cardiac complications.

Just over half of the participants (52\%) estimated that at least between 1 and 5 patients they were following, could not benefit from cardiovascular surgery.

And more than a third (39\%) estimated that at least between 1 and 5 patients they were following died during the confinement period.

An unusual increase in certain cardiovascular events or reasons for consultation/hospitalization was noted by the participants. These manifestations are dominated by heart failure (53.9\%), dyspnea (13.4\%) and venous thromboembolic disease (11.7\%) (Figure 4). 

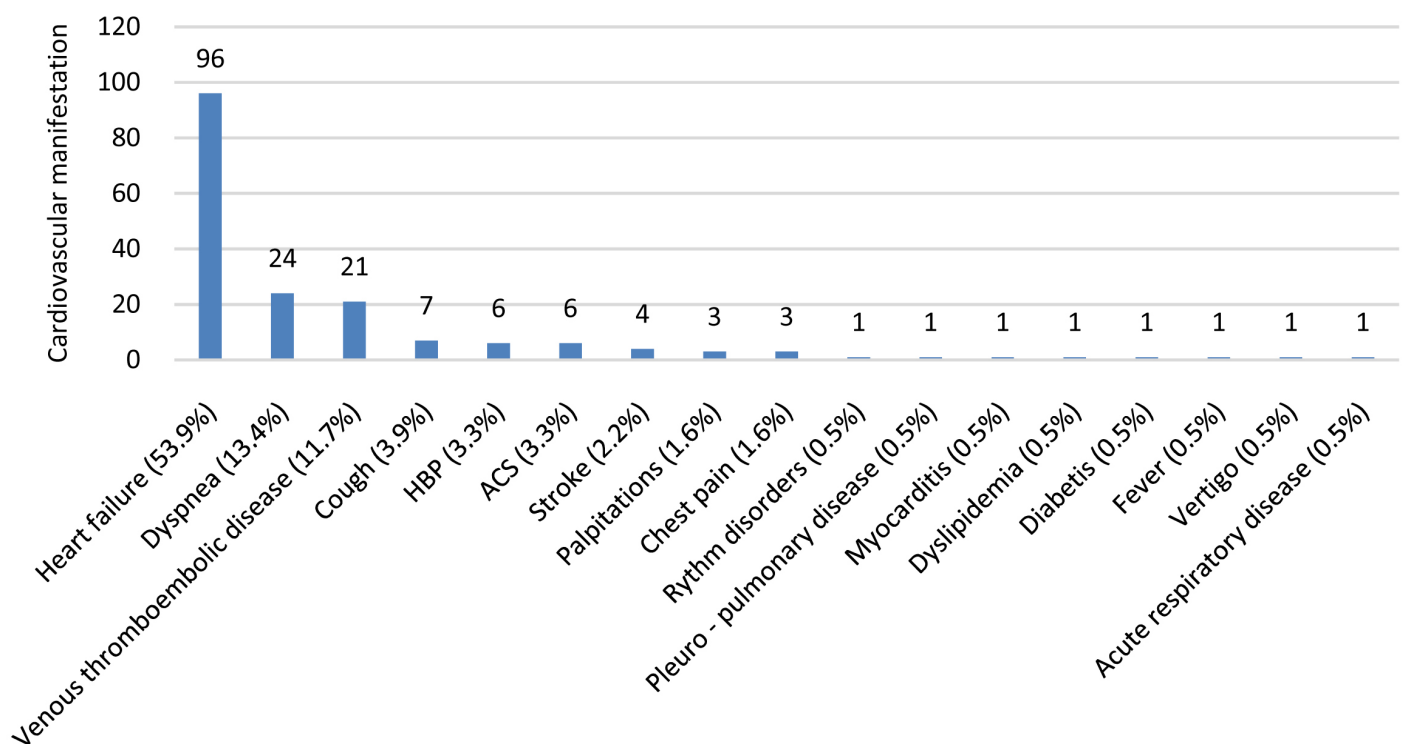

Numbre of responses

Figure 4. Distribution of responses according to the cardiovascular manifestations that appeared during the pandemic. HBP: High blood pressure; ACS: Acute Coronary Syndrome.

\section{Discussion}

Patients with heart disease are mostly treated in the country's capital, Dakar. Some regions of Senegal did not register any participation which suggests that they suffer from a shortage of health professionals assigned to Cardiology. Health centers and health posts, despite their low participation rate in our study, also contribute to the patients in cardiology treatment. The requisition of cabins, areas or an entire structure for the isolation or care of patients with COVID-19 has a considerable impact on the reduction of the inpatient capacity of cardiology structures which, even in normal times, cannot admit certain patients for lack of space. The reduction in medical activity (consultation, hospitalization, non-invasive examinations, medical care) can be explained by the postponement of non-urgent appointments to avoid gatherings in sanitary areas, but also by the confinement and the fear of some patients of exposing themselves to the risk of contamination in health structures. This has also been observed in several health structures in France [5]. However, a certain number of patients would require hospital treatment because of their condition, the follow-up of their chronic disease or an emergency such as stroke or myocardial infarction whose fast management is essential. The decline in interventional activity can be explained by the postponement of appointments for non-urgent interventional procedures, by the prevention of the risk of exposure of personnel in catheterization rooms, but also by confinement and difficulties in evacuating patients. The studies by Leor [6] and Tam [7] also concluded that there was a significant reduction in interventional management in cardiology.

The state of health emergency declared in Senegal but also in other countries of the world may explain the unavailability of certain drugs, which mostly come 
from abroad and which have encountered a problem in their chain of production or distribution.

In addition to the lack of protective equipment, contact with positive cases, certain clinical presentations of COVID-19 can be insidious because they are asymptomatic or can mimic certain functional or physical signs encountered in cardiac pathologies. This gives exposed professionals a feeling of insecurity in their work environment. In a study including 6510 healthcare professionals (including 1794 nurses and 904 administrative staff), Wilkins [8] concluded that healthcare workers had slightly lower risks of SARS-CoV-2 infection compared to other studies in the New York region [9] and Spain [10], and a similar rate of seropositivity reported in a study conducted in Denmark [11]. Of all professional groups, nurses were at the highest risk from exposure at work. The lower risk of infection from the data from the Wilkins study is explained by the effectiveness of protective equipment and stringent infection control policies.

The high prevalence rate of heart failure in our series is explained by the fact that the diagnosis of heart failure was most often made on the basis of non-specific functional and physical signs found in other extra-cardiac pathologies. The use of Brain Natriuretic Peptide (BNP) was rare. We did not find any cases of myocarditis that could constitute an etiology of these heart failures. This is explained by the difficulty encountered in making the diagnosis which most often requires the performance of magnetic resonance imaging (MRI).

Some patients were unable to benefit from Cardiovascular Surgery treatment during the confinement period. This is due to the fact that the Department of Thoracic and Cardiovascular Surgery and the Cardiopediatric Center of CUOMO have been requisitioned to hospitalize COVID-19 patients. Lazaros [12] also observed a significant decrease in the number of cardiac surgery operations during the pandemic. The death of some patients during confinement can be explained by the fact that they could not be treated in time and adequately.

\section{Conclusions}

The spread of the new SARS-CoV-2 coronavirus, broken out in China in December 2019, led to a pandemic as early as March 2020 forcing every healthcare system in affected countries to adapt quickly. The COVID-19 pandemic is thus responsible for a change in the care structures for Cardiology patients in Senegal resulting in the requisition of health structures and reduction in medical and intervention activities. According to the results of our study, we can say that in times of pandemic, the plans to be implemented in Cardiology structures in Senegal would revolve around:

Reducing the staff shortage; the equipment of resuscitation structures (in all regions of Senegal); the establishment of pandemic management structures and a network of biological laboratories disseminated throughout the country; the preparation of stocks of protective equipment and stocks of critical drugs; the implementation of structures requisition plans. This would avoid paralyzing the 
activity of essential structures such as the Thoracic and Cardiovascular Surgery Department and the CUOMO Cardio-Pediatric Center.

\section{Authors' Contribution}

All the authors contributed to the conduct of this work. All authors have read and approved the latest version of this manuscript.

\section{Conflicts of Interest}

The authors declare no conflict of interest.

\section{References}

[1] Shereen, M.A., Khan, S., Kazmi, A., Bashir, N. and Siddique, R. (2020) COVID-19 Infection: Origin, Transmission, and Characteristics of Human Coronaviruses. Journal of Advanced Research, 24, 91-98. https://doi.org/10.1016/j.jare.2020.03.005

[2] Wong, G., Liu, W., Liu, Y., Zhou, B., Bi, Y. and Gao, G.F. (2015) MERS, SARS, and Ebola: The Role of Super-Spreaders in Infectious Disease. Cell Host \& Microbe, 18, 398-401. https://doi.org/10.1016/j.chom.2015.09.013

[3] WHO (2019) Nouveau Coronavirus (2019-nCoV). Who.int. https://www.who.int/fr/emergencies/diseases/novel-coronavirus-2019

[4] Gouv.sn. (2019). http://www.sante.gouv.sn

[5] Barro, K., Malone, A., Mokede, A. and Chevance, C. (2020) Management of the COVID-19 Epidemic by Public Health Establishments-Analysis by the Fédération Hospitalière de France. Journal of Visceral Surgery, 157, S19-S23. https://doi.org/10.1016/j.jviscsurg.2020.04.011

[6] Rodríguez-Leor, O., Cid-Álvarez, B., Ojeda, S., Martín-Moreiras, J., Ramón Rumoroso, J. and López-Palop, R. (2020) Impact of the COVID-19 Pandemic on Interventional Cardiology Activity in Spain. REC Interventional Cardiology (English Edition), 2, 82-89. https://doi.org/10.24875/RECICE.M20000123

https://www.recintervcardiol.org/en/health-management/impact-of-the-covid-19-p andemic-on-interventional-cardiology-activity-in-spain

[7] Tam, C.-C.F., Cheung, K.S., Lam. S., Wong, A., Yung, A. and Sze, M. (2020) Impact of Coronavirus Disease 2019 (COVID-19) Outbreak on ST-Segment-Elevation Myocardial Infarction Care in Hong Kong, China. Circulation: Cardiovascular Quality and Outcomes, 13, e006631. https://doi.org/10.1161/CIRCOUTCOMES.120.006631

[8] Wilkins, J., Gray, E.L., Wallia, A., Hirschhorn, L., Zembower, T. and Ho, J. (2020) Seroprevalence and Correlates of SARS-CoV-2 Antibodies in Healthcare Workers in Chicago. Open Forum Infectious Diseases, 8, Article ID: ofaa582. https://doi.org/10.1101/2020.09.11.20192385

[9] Moscola, J., Sembajwe, G., Jarrett, M., Farber, B., Chang, T. and McGinn, T. (2020) Prevalence of SARS-CoV-2 Antibodies in Health Care Personnel in the New York City Area. JAMA, 324, 893-895. https://doi.org/10.1001/jama.2020.14765

[10] Pollán, M., Pérez-Gómez, B., Pastor-Barriuso, R., Oteo, J., Hernán, M.A. and Pérez-Olmeda, M. (2020) Prevalence of SARS-CoV-2 in Spain (ENE-COVID): A Nationwide, Population-Based Seroepidemiological Study. Lancet, 396, 535-544. https://doi.org/10.1016/S0140-6736(20)31483-5

[11] Iversen, K., Bundgaard, H., Hasselbalch, R.B., Kristensen, J.H., Nielsen, P.B. and Pries-Heje, M. (2020) Risk of COVID-19 in Health-Care Workers in Denmark: An 
Observational Cohort Study. The Lancet Infectious Diseases, 20, 1401-1408.

https://doi.org/10.1016/S1473-3099(20)30589-2

https://read.qxmd.com/read/32758438/risk-of-covid-19-in-health-care-workers-indenmark-an-observational-cohort-study

[12] Lazaros, G., Oikonomou, E., Theofilis, P., Theodoropoulou, A., Triantafyllou, K. and Charitos, C. (2020) The Impact of COVID-19 Pandemic on Adult Cardiac Surgery Procedures. Hellenic Journal of Cardiology, 62, 231-233.

https://doi.org/10.1016/j.hjc.2020.07.001

https://covid19.elsevierpure.com/en/publications/the-impact-of-covid-19-pandemic -on-adult-cardiac-surgery-procedur-2 